\title{
Examination of bond strength and mechanical properties of Y-TZP zirconia ceramics with different surface modifications
}

\author{
Hiroaki YAMAGUCHI' ${ }^{1}$ Satoshi INO ${ }^{1}$, Naho HAMANO ${ }^{1}$, Shusaku OKADA² and Toshio TERANAKA² \\ ${ }^{1}$ Division of Removable Prosthetics, Department of Oral and Maxillofacial Rehabilitation, Kanagawa Dental College, 82 Inaoka-cho, Yokosuka, \\ Kanagawa 238-8580, Japan \\ ${ }^{2}$ Division of Restorative Dentistry, Department of Oral Medicine, Kanagawa Dental College, 82 Inaoka-cho, Yokosuka, Kanagawa 238-8580, Japan \\ Corresponding author, Satoshi INO; E-mail: inosatos@kdcnet.ac.jp
}

\begin{abstract}
The purpose of our study was to evaluate the effects of surface modifications on the bond strength between veneering porcelains and Yttria-stabilized tetragonal zirconia (Y-TZP). In a bond strength tests, the effect of control, $70 \mu \mathrm{m}$ alumina-sandblasting, $30 \mu \mathrm{m}$ and $110 \mu \mathrm{m}$ silica-coating of the Y-TZP surface on bonding were evaluated with veneering porcelains. In addition, the effect of surface modification on the flexural strength of Y-TZP was also evaluated. The data was analyzed using one-way ANOVA and Tukey test. All specimens showed bond strength values in excess of $25 \mathrm{MPa}$, the minimum allowed by ISO9693. In addition, significantly differences were found between the control and the $30 \mu \mathrm{m}$ silica-coated. On the other hand the flexural strength of Y-TZP does not significantly difference for any surface modification. These results indicate that silica-coating may provide an effective pre-treatment for this enhancement of the bond strength while maintaining the strength of Y-TZP.
\end{abstract}

Keywords: Y-TZP, Silica-coating, Bond strength, Flexural strength

\section{INTRODUCTION}

In recent years, the use of ceramic for dental restorations has increased because of three factors: aesthetics, biocompatibility, and high mechanical toughness ${ }^{1)}$. Yttria-stabilized tetragonal zirconia (Y-TZP) is used as the standard core material in all ceramics for medical and dental restorations. Production of a stable, strong product was enabled by the introduction of a CAD/CAM system into the design and processing of Y-TZP ${ }^{2-4)}$. Zirconium dioxide has superior mechanical properties due to a unique transformation toughening mechanism. The mechanism is that $\mathrm{ZrO}_{2}$ has three allotropes: the monoclinic phase is stable up to $1,170^{\circ} \mathrm{C}$, where it transforms into the tetragonal phase, which is stable up to $2,370^{\circ} \mathrm{C}$, and then the cubic phase exists up to the melting point of $2,680^{\circ} \mathrm{C}^{5,6}$. The transformation of the tetragonal phase to the monoclinic phase occurs based on stress and the mechanical energy load (e.g.- sandblasting, grinding) or thermal energy ${ }^{7-12}$. There is a large volume expansion $(3-5 \%)$ on going from the tetragonal to the monoclinic phase, which prevents cracks in the zirconia framework, making zirconia a potentially superior material to other dental ceramics ${ }^{13,14)}$.

This results in the higher fracture toughness of zirconia and Y-TZP when compared with conventional ceramics ${ }^{15-17)}$. On the other hand, any cracking or chipping of veneered porcelains is important in clinical use, but the mechanism of surface destruction of veneering porcelains on a Y-TZP framework is poorly studied. Therefore, intensive study of the bond strength of veneered porcelains on the Y-TZP framework is needed. Aboushelib et $a l .{ }^{18)}$ indicated that sandblasting is a popular method of enhancing bond strength by increasing surface roughness and providing undercuts. On the other hand, Guazzato et $a l^{16)}$ indicated that cracking and strength degradation of the zirconia surface may result from excessive sandblasting. Furthermore, sandblasting induces the transformation from the tetragonal to the monoclinic phase, subsequently resulting in compressive stress $^{19,20)}$, and the coefficient of thermal expansion of monoclinic zirconia $\left(7.5 \cdot 10^{-6} / \mathrm{K}\right)$ is significantly lower than that of tetragonal zirconia $\left(10.8 \cdot 10^{-6} / \mathrm{K}\right)^{21}$. With this in mind, the effect of surface modifications on the mechanical strength of Y-TZP and the bond quality to veneering porcelains is an intensely discussed subject ${ }^{13,222}$. Furthermore, it is surmised that the monoclinic phase produced by sandblasting induces tensile stress, leading to cracking and chipping of the veneering porcelain. Therefore, heat treatment after sandblasting can be performed to induce the reverse the monoclinic to the tetragonal phase transformation in order to retrieve the coefficient of thermal expansion of the tetragonal zirconia and release the tensile stresses ${ }^{23)}$. However, heat treatment after sandblasting reduces the volume of the monoclinic phase, thus reducing the flexural strength ${ }^{24)}$.

Kern et $a l . .^{25,26)}$ indicated that the silica-coating method is an effective method for adhering alumina or zirconia ceramics and resin. However, the effect of bond strength between the Y-TZP and the veneering porcelain was not discussed. Thus, this work examines silicacoating as a method to form a silicate layer on the zirconia surface of a metal, resin, or ceramic, and evaluates the improvement in the bond strength between the Y-TZP and the veneering porcelain due to silica-coating.

\section{MATERIALS AND METHODS}

$Y$-TZP framework preparation

The Y-TZP framework (25 mm long, $3 \mathrm{~mm}$ wide, $0.5 \mathrm{~mm}$ 
Table 1 Materials used

\begin{tabular}{llcl}
\hline Brand name & \multicolumn{1}{c}{ Composition } & Production no. & \multicolumn{1}{c}{ Manufacturer } \\
\hline Lava Zirconia & 3 mol\% $\mathrm{Y}_{2} \mathrm{O}_{3}-\mathrm{ZrO}_{2}$ & 393115 & 3M ESPE, Seefeld, Germany \\
Cerabien ZR (Shade Base) & Feldspathic porcelain & 019121 & Noritake Dental Supply, Aichi, Japan \\
Cerabien ZR (Body) & Feldspathic porcelain & 018986 & Noritake Dental Supply, Aichi, Japan \\
Cerabien ZR (Enamel) & Feldspathic porcelain & 018725 & Noritake Dental Supply, Aichi, Japan \\
HI ALUMINAS & $70 \mu \mathrm{m} \mathrm{Al} \mathrm{O}_{3}$ & 1107 & Shofu, Kyoto, Japan \\
Rocatec $^{\circledR}$-Soft & Silica cont. $30 \mu \mathrm{m} \mathrm{Al}_{2} \mathrm{O}_{3}$ & 016 & 3M ESPE, Seefeld, Germany \\
Rocatec $^{\circledR}$-Plus & Silica cont. $110 \mu \mathrm{ml}_{2} \mathrm{O}_{3}$ & 412 & 3M ESPE, Seefeld, Germany \\
\hline
\end{tabular}

thick) was obtained via standard ISO 9693:1999 (E) methods $^{27-29)}$ (Lava zirconia, 3M ESPE, Seefeld, Germany), and pre-sintered zirconium oxide blocks pre-sintered zirconium oxide blocks (Table 1) were milled using a CAD/CAM system (Lava, 3M ESPE, Seefeld, Germany), and they were cut into plates using an automatic precision cutter, (ISOMET ${ }^{\circledR}$, Buehler Ltd., IL, USA), then the plates polished under running water using \#600, \#1000, and \#2500 waterproof abrasive papers (Buehler Ltd., IL, USA). They were then cleaned and dried, with a final sintering at $1,500^{\circ} \mathrm{C}$ for $5 \mathrm{~h}$.

\section{Surface modified and with/without heat treatment of} framework

Thirty-five frameworks were prepared and split into 7 groups of 5. Each of the frameworks prepared was subjected to one of four surface modifications:

1) No surface modification, to serve as the control (denoted "cont")

2) Alumina-sandblasting (70 $\mu \mathrm{m}$ mean grain size, "Al")

3) $\mathrm{Al}$ with heat treatment at $650-1,000^{\circ} \mathrm{C}$ for $5 \mathrm{~min}$ (“Al.h")

4) Silica-coating with Rocatec ${ }^{\circledR}$ system $(30 \mu \mathrm{m}$ mean grain size, "Rs")

5) Rs with heat treatment ("Rs.h")

6) Silica-coating with Rocatec ${ }^{\circledR}$ system (110 $\mu \mathrm{m}$ mean grain size, "Rp")

7) Rp with heat treatment ("Rp.h")

Mechanical modification of each material was performed using a sandblaster (Hi Blaster Ovaljet, Shofu, Kyoto, Japan) at a distance of $10 \mathrm{~mm}$ from the Y-TZP framework, under a pneumatic pressure of $0.4 \mathrm{MPa}$, with an injection time of $10 \mathrm{~s}$, and each framework was then ultrasonically cleaned for 5 min. Subsequently, groups 3, 5 and 7 were subjected to heat treatment at $650-1,000^{\circ} \mathrm{C}$ using $45^{\circ} \mathrm{C} /$ min rise speed and kept at $1,000^{\circ} \mathrm{C}$ for $5 \mathrm{~min}$ (Austromat D4, Dekema Dental-Keramiköfen GmbH \& Co, Freilassing, Germany).

\section{$X$-ray diffraction}

The amount of transformation which was induced by either no surface modification, sandblasting (Al) before and after heat treatment at $650-1,000^{\circ} \mathrm{C}$ for $5 \mathrm{~min}$, and silica-coating ( $\mathrm{Rs}, \mathrm{Rp}$ ) before and after heat treatment was determined by measuring the peak intensity ratio in the X-ray diffraction (XRD) (MiniFlex II, Rigaku, Tokyo, Japan) pattern of the Y-TZP specimens (12 mm in length,
$3 \mathrm{~mm}$ wide and $0.5 \mathrm{~mm}$ thick), using $\mathrm{Cu}-\mathrm{K} \alpha$ radiation at $30 \mathrm{kV}$ and $15 \mathrm{~mA}$. Five samples of each modification were examined. The diffractograms were obtained at a scan speed of $1.0 \% \mathrm{~min}$. The monoclinic peak intensity ratio, $X_{M}$, was calculated using the Garvie and Nicholson method $^{30)}$ as follows:

$$
X_{M}=\frac{I_{M}(11 \overline{1})+I_{M}(111)}{I_{M}(11 \overline{1})+I_{M}(111)+I_{T}(111)}
$$

where $I_{T}$ and $I_{M}$ represent the integrated intensity (area under the peak) of the tetragonal (111) and monoclinic (111) and $(11 \overline{1})$ peaks, respectively, around $30^{\circ}, 31^{\circ}$, and $28^{\circ}$. The monoclinic volume content, $V_{M}$, was calculated using the method of Toraya et al. ${ }^{31)}$.

$$
V_{M}=\frac{1.311 X_{M}}{1+0.311 X_{M}}
$$

\section{Surface free energy measurements}

Advancing contact angles and the surface free energy of Y-TZP specimens manufactured using the same method described in section Surface modified and with/without heat treatment of framework (cont, $\mathrm{Al}, \mathrm{Rs}, \mathrm{Rp}$ ) were measured using an automatic dynamic contact analyzer (DCA-VZ, Kyowa Interface Science, Saitama, Japan) with two test liquids (water and diiodomethane). Each specimen was measured three times in both of the two liquids at room temperature. The surface free energy was calculated from the contact angles of these specimens with software (FAMAS, Kyowa Interface Science, Saitama, Japan) using the Owen-Wendt method ${ }^{32}$. Data were analyzed via one-way analysis of variance (ANOVA) and then with Tukey's multiple comparison procedure $(p<0.01)$.

\section{Surface roughness measurements}

The surface roughness of each surface-modified Y-TZP specimen was measured using a Surface roughness tester (Surfcom 590A, Tokyo Seimitu, Tokyo, Japan). The arithmetic mean deviation of the assessed profile (Ra) and the maximum height of the profile $(\mathrm{Rz})$ were measured under the following conditions: cut-off value, $0.8 \mathrm{~mm}$; measurement length, $4.0 \mathrm{~mm}$; and measurement speed, $0.3 \mathrm{~mm} / \mathrm{s}$. 
Porcelain-veneered Y-TZP framework

A porcelain veneer (Cerabien ZR, Noritake Dental Supply, Aichi, Japan) was applied to the Y-TZP modified frameworks which was modified (cont, Al, Rs, Rp) either with or without heat treatment. First, an $8 \mathrm{~mm}$ long $\times 3$ $\mathrm{mm}$ wide $\times 1 \mathrm{~mm}$ thick layer of the shade base porcelain was fired, then an $8 \mathrm{~mm} \times 3 \mathrm{~mm} \times 0.2 \mathrm{~mm}$ layer of body porcelain was fired, then a $1 \mathrm{~mm}$ thick layer of body porcelain was fired, and finally, a $1 \mathrm{~mm}$ thick layer of enamel porcelain was fired on each framework, to form a rectangular porcelain veneer $8 \mathrm{~mm}$ long $\times 3 \mathrm{~mm}$ wide $\times 1.1$ $\mathrm{mm}$ thick. Firing was accomplished in a porcelain oven (Austromat D4, Dekema Dental-Keramiköfen) according to the manufacturers' recommendations.

\section{Bond strength and flexural strength measurements}

The bond strength between the Y-TZP framework and the veneering porcelain was calculated using the three-point bending test, according to the guidelines set forth in ISO 9693:1999 $(\mathrm{E})^{27-29)}$. It was assumed that the debonding/crack initiation strength standards of ISO 9693 are applicable to the bonding tests of zirconia and veneering porcelain, although this specification specifically prescribes the method for testing the bonding strength between a metal substrate and a veneering porcelain. The sample holder of the universal testing machine (EZ Test, Shimadzu, Kyoto, Japan) had a 20 mm span between the two arms. The load was applied at a constant speed of $1.0 \mathrm{~mm} / \mathrm{min}$ until fracture occurred. The mean bond strength values were analyzed by one-way ANOVA and Tukey's multiple comparison test to determine whether significant differences $(p<0.05$ and $p<0.01$ ) were present.

Subsequently, the flexural strength of the Y-TZP was calculated using a three-point bending test in the EZ Test. The sample holder span was again $20 \mathrm{~mm}$, and the load was again applied at a constant speed of $1.0 \mathrm{~mm} /$ min until fracture occurred. Data were analyzed using ANOVA and then via Tukey's multiple comparison procedure $(p<0.05)$.

\section{Surface analysis by EPMA}

The $\mathrm{Si}$ and $\mathrm{Zr}$ distribution on the cont and modified Y-TZP base materials was evaluated using an electron probe micro analyzer (EPMA8705, Shimadzu, Kyoto, Japan). Measurement parameters were set as follows: accelerating voltage, $20 \mathrm{kV}$; beam current, $15 \mathrm{nA}$; and measurement time, $0.05 \mathrm{~s}$. For the Y-TZP specimens, the distribution of $\mathrm{Si}$ over the fracture surface after flexural strength tests was analyzed. This data of the distribution of Si over the part which remained of the porcelain in fracture surface was taken five points by random sampling method, and analyzed via ANOVA and Tukey's procedure $^{33)}(p<0.01)$.

\section{RESULTS}

Figure 1 shows the XRD patterns of the cont and modified Y-TZP. Compared to the control, the detectable monoclinic peaks, with a marked preference of the M $(11 \overline{1})$, increased for the alumina-sandblasted (Al) and silica-coated ( $\mathrm{Rs}, \mathrm{Rp}$ ) samples. However, for samples heat treated after surface modification, there was almost no change in comparison with the control.

Table 2 shows the monoclinic $\mathrm{ZrO}_{2}$ content derived from the XRD patterns using Eqs. (1) and (2). The monoclinic $\mathrm{ZrO}_{2}$ content of the silica-coated (Rs: $2.04 \pm 0.30), \quad(\mathrm{Rp}: 2.18 \pm 0.22)$ groups without heat treatment was significantly larger than the unmodified group (cont: $0.66 \pm 0.40)(p<0.01)$, and the content of the silica-coated group (Rp: $2.18 \pm 0.22$ ) was significantly larger than the alumina-sandblasted (Al: 1.16 \pm 1.08 )

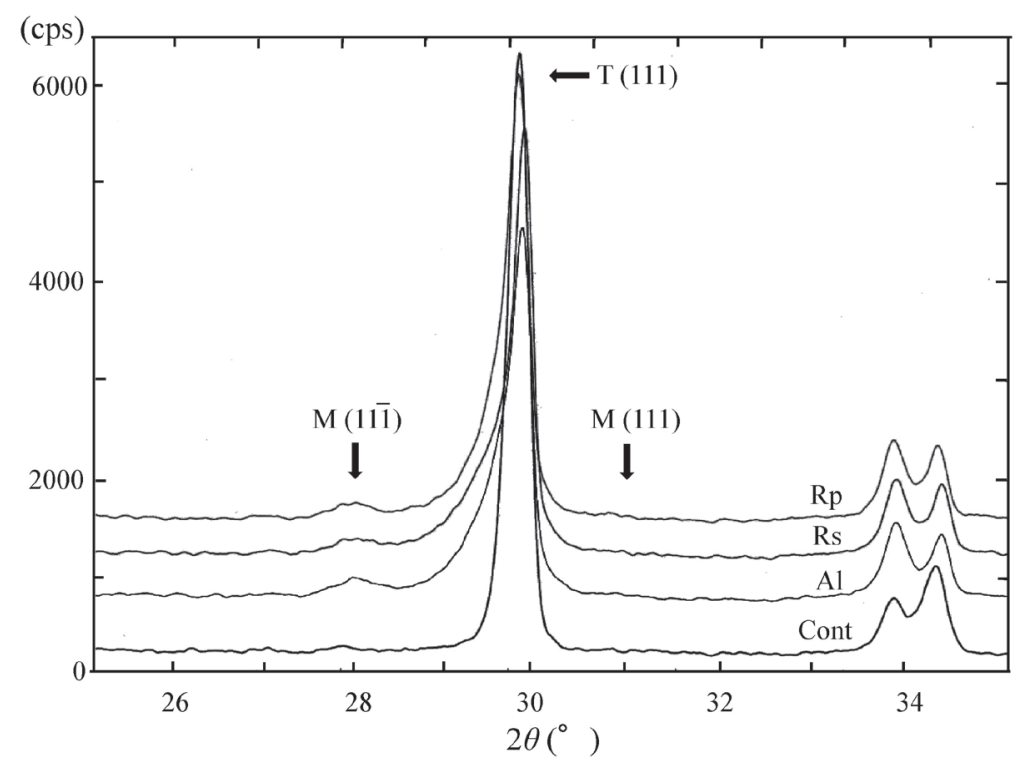

Fig. 1 XRD pattern obtained from no surface modification (cont), alumina-sandblasted (Al), and silica-coated (Rs, Rp) samples of Y-TZP. 
Table 2 Relative amounts of monoclinic zirconia (volume \%) as verified by X-ray diffractometry

\begin{tabular}{lcc}
\hline \multirow{2}{*}{ Parameter } & \multicolumn{2}{c}{ Monoclinic volume content in \% (SD) } \\
\cline { 2 - 3 } & without heat treatment & with heat treatment \\
\hline Control & $0.66(0.4)$ & $0.44(0.62)$ \\
Alumina-sand-70 $\mu \mathrm{m}$ & $1.16(1.08)$ & $0.09(0.21)$ \\
Silica-coating-30 $\mu \mathrm{m}$ & $2.04(0.30)$ & $0.19(0.26)$ \\
Silica-coating-110 $\mu \mathrm{m}$ & $2.18(0.22)$ & \\
\hline
\end{tabular}

Table 3 Statistical significance of the mean surface free energy values of each sample in Fig. $2 . * *:(p<0.01)$

\begin{tabular}{|c|c|c|c|c|}
\hline & Cont & & & \\
\hline Cont & & $\mathrm{Al}$ & & \\
\hline $\mathrm{Al}$ & $* *$ & & $\mathrm{Rs}_{\mathrm{s}}$ & \\
\hline $\mathrm{Rs}_{\mathrm{S}}$ & $* *$ & $* *$ & & $\mathrm{Rp}$ \\
\hline $\mathrm{Rp}$ & $* *$ & $* *$ & $* *$ & \\
\hline
\end{tabular}

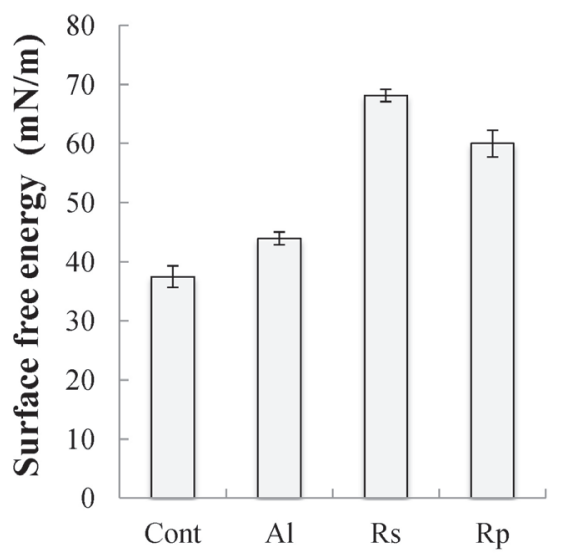

Fig. 2 Surface free energy values $(\mathrm{mN} / \mathrm{m})$ and their standard deviations for the different surfacemodified Y-TZP samples.

without heat treatment group $(p<0.05)$. However, after heat treatment at $650-1,000^{\circ} \mathrm{C}$ for $5 \mathrm{~min}$ for the surface modified groups, the monoclinic $\mathrm{ZrO}_{2}$ content decreased to a level not significantly different from the control

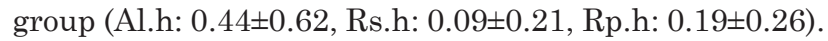
Furthermore, silica-coated, with heat treatment samples (Rs.h, Rp.h) had values significantly lower than silicacoated, without heat treatment samples ( $\left.\mathrm{R}_{\mathrm{s}}, \mathrm{Rp}\right)$ $(p<0.01)$.

Figure 2 shows the mean surface free energy values of the surface modified Y-TZP samples. Table 3 shows the statistical significance of the surface free energy values of each sample. The mean surface free energy values were cont, $37.47 \pm 1.81 \mathrm{mN} / \mathrm{m}$; Al, $43.9 \pm 1.08 \mathrm{mN} / \mathrm{m}$; $\mathrm{Rs}, 68.1 \pm 1.06 \mathrm{mN} / \mathrm{m}$; and $\mathrm{Rp}, 60 \pm 2.26 \mathrm{mN} / \mathrm{m}$. The surface free energy value of the $\mathrm{Al}$ group was significantly higher
Table 4 Surface roughness values of Y-TZP for cont, Al, Rs, and Rp samples

\begin{tabular}{lcc}
\hline Material & \multicolumn{2}{c}{ Y-TZP } \\
\hline Parameter & Ra in $\mu \mathrm{m}(\mathrm{SD})$ & $\mathrm{Rz}$ in $\mu \mathrm{m}(\mathrm{SD})$ \\
\hline Control & $0.19(0.03)$ & $1.72(0.23)$ \\
Alumina-sand-70 $\mu \mathrm{m}$ & $0.41(0.06)$ & $3.74(0.65)$ \\
Silica-coating-30 $\mu \mathrm{m}$ & $0.34(0.04)$ & $3.18(0.53)$ \\
Silica-coating-110 $\mu \mathrm{m}$ & $0.50(0.10)$ & $4.57(0.79)$ \\
\hline
\end{tabular}

than control $(p<0.01)$. Rp group was significantly higher than control, $\mathrm{Al}(p<0.01)$. Furthermore $\mathrm{Rs}$ group value was significantly higher than the other groups $(p<0.01)$.

Table 4 shows the mean surface roughness values and standard deviations of the Y-TZP samples. The surface roughness values of the surface-modified groups were higher than the control group. The Rs group value was lower than the $\mathrm{Al}$ and Rp groups.

Figure 3 shows the mean bond strength and flexural strength values of the porcelain-veneered Y-TZP with and without heat treatment. Table 5 and Table 6 show the statistical significance of bond strength and flexural strength values of the each sample. For the control group, the bond strength was $26.66 \pm 1.31 \mathrm{MPa}$. For the $\mathrm{Al}, \mathrm{Rs}$, and $\mathrm{Rp}$ samples without heat treatment, the bond strength values of specimens were 25.78 \pm 1.00 , $30.47 \pm 1.99$, and $29.11 \pm 1.62 \mathrm{MPa}$, respectively. After heat treatment, the bond strength values of the Al.h, Rs.h, and Rp.h specimens were 28.84 \pm 2.30 , 30.1 \pm 2.12 , and 29.84 $\pm 1.04 \mathrm{MPa}$, respectively. The bond strength value of the Rp.h group was significantly higher than the $\mathrm{Al}$ group $(p<0.05)$. The group of both $\mathrm{Rs}$ and Rs.h was significantly higher than the Al group $(p<0.01)$ and the control $(p<0.05)$. On the other hand, the other groups showed no significant difference from the control. The flexural strength value of the control was $877.08 \pm 39.19$ $\mathrm{MPa}$, while the values for the $\mathrm{Al}, \mathrm{Rs}$, and $\mathrm{Rp}$ groups, without heat treatment, were $1,021.32 \pm 63.57$, $944.7 \pm 208.18$, and $984.86 \pm 42.39 \mathrm{MPa}$, respectively- not significantly different. On the other hand, after heat treatment, the flexural strength values were $1,005.62 \pm 80.03,1,051.64 \pm 154.13$, and $1,042.63 \pm 70.62$ $\mathrm{MPa}$ for the Al.h, Rs.h, and Rp.h groups, respectively again not significantly different.

Figure 4-a) shows the Si EPMA mappings and Fig. 4-b) shows the Zr EPMA mappings of the modified Y-TZP 
a)

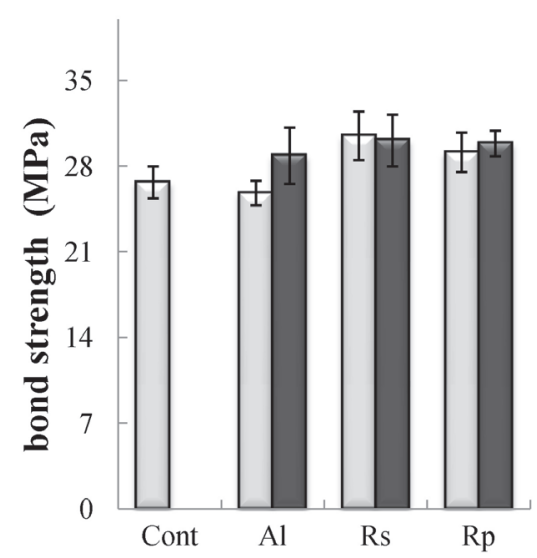

b)

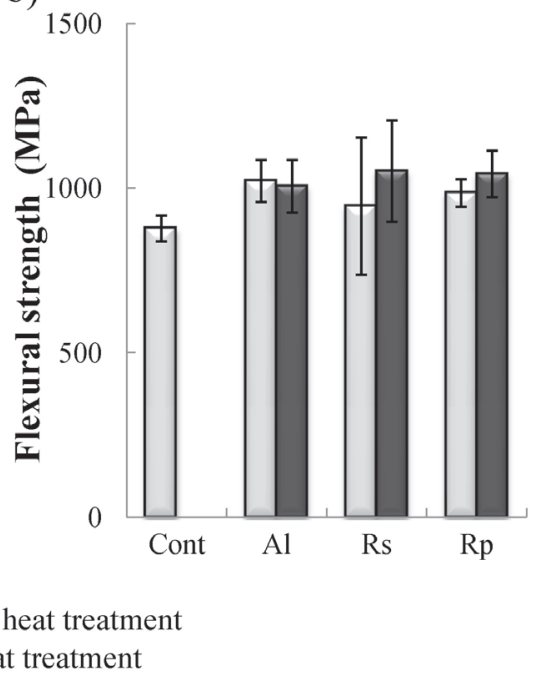

Fig. 3 a) Bond strength values of the porcelain-veneered Y-TZP and b) flexural strength of Y-TZP for different surface modification methods, with/without heat-treatment.

Table 5 Statistical significance of the mean bond strength values of the porcelain-veneered Y-TZP for each sample in Fig. 3 -a). ${ }^{* *}:(p<0.01) *:(p<0.05)$

\begin{tabular}{|c|c|c|c|c|c|c|c|}
\hline 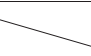 & Cont & & & & & & \\
\hline Cont & $x$ & $\mathrm{Al}$ & & & & & \\
\hline $\mathrm{Al}$ & - & 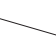 & Al.h & & & & \\
\hline Al.h & - & - & $x$ & Rs & & & \\
\hline Rs & $*$ & $* *$ & - & $x$ & Rs.h & & \\
\hline Rs.h & $*$ & $* *$ & - & - & 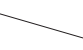 & $\mathrm{Rp}$ & \\
\hline $\mathrm{Rp}$ & - & - & - & - & - & 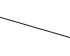 & Rp.h \\
\hline Rp.h & - & $*$ & - & - & - & - & \\
\hline
\end{tabular}

Table 6 Statistical significance of the mean flexural strength values of the porcelain-veneered Y-TZP for each sample in Fig. 3-b)

\begin{tabular}{|c|c|c|c|c|c|c|c|}
\hline$\gamma$ & Cont & & & & & & \\
\hline Cont & $x$ & $\mathrm{Al}$ & & & & & \\
\hline $\mathrm{Al}$ & - & $\gamma$ & Al.h & & & & \\
\hline Al.h & - & - & 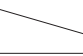 & $\mathrm{Rs}_{\mathrm{s}}$ & & & \\
\hline $\mathrm{Rs}$ & - & - & - & 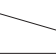 & Rs.h & & \\
\hline Rs.h & - & - & - & - & $\gamma$ & $\mathrm{Rp}$ & \\
\hline $\mathrm{Rp}$ & - & - & - & - & - & 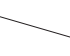 & Rp.h \\
\hline Rp.h & - & - & - & - & - & - & \\
\hline
\end{tabular}


(cps) a)

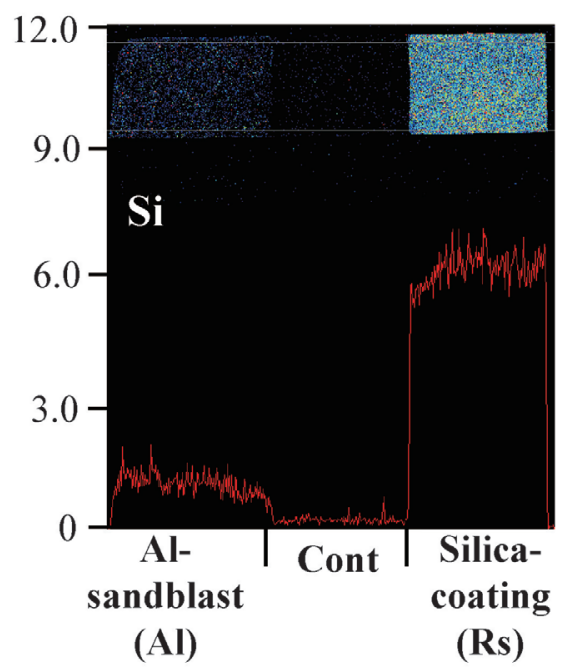

(cps) b) $\sqcup 2 \mathrm{~mm}$

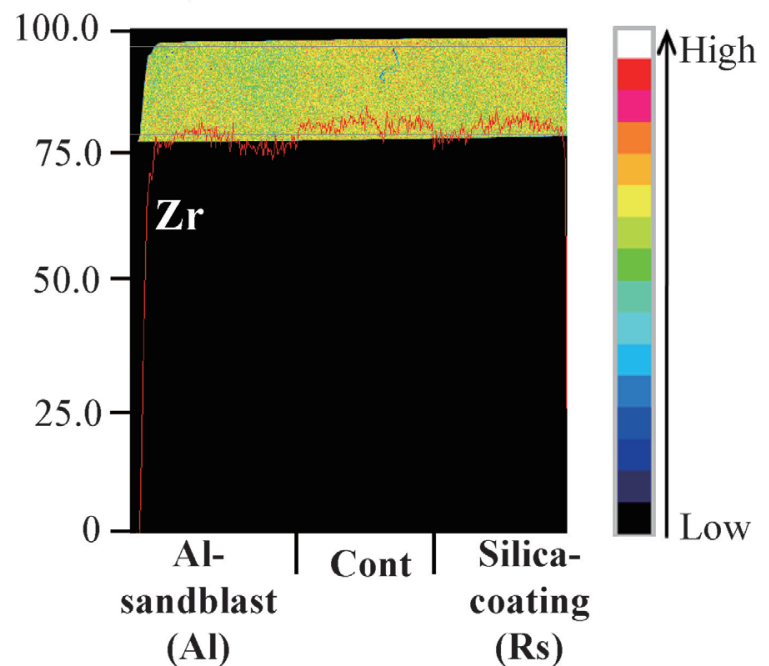

Fig. 4 a) Si mapping by EPMA of Y-TZP surfaces after different surface modifications cont, Al, Rs). The red line shows a rise in Si concentration. b) Zr mappings by EPMA of Y-TZP surfaces after different surface modifications (cont, $\mathrm{Al}, \mathrm{Rs}$ ).

\section{Si mappings}

a)

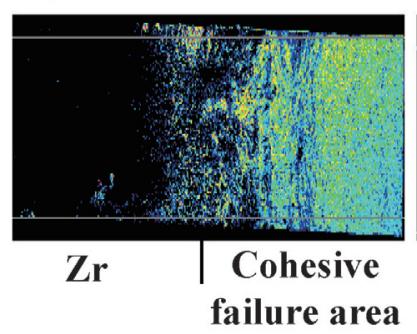

failure area b)

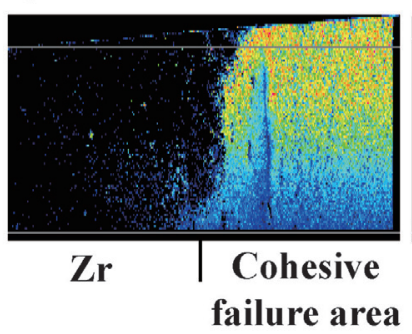

c)

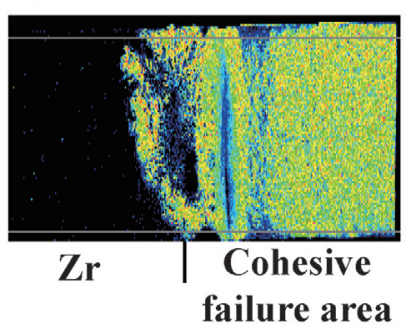
$2.0 \mathrm{~mm}$

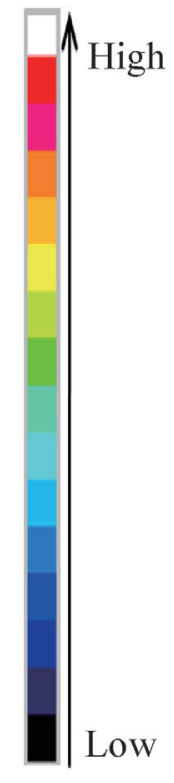

d)

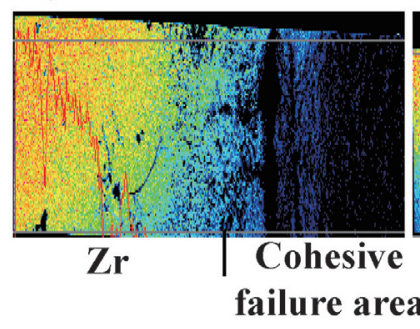

e)

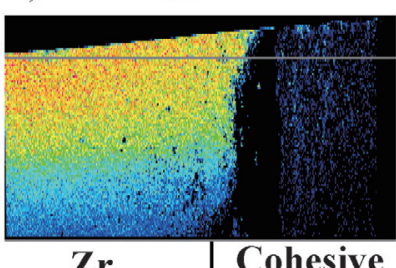

failure area

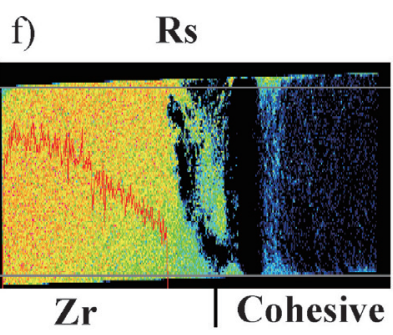

failure area

Fig. 5 a)-c) Si mappings of the fracture surfaces of porcelain-veneered Y-TZP for different surface modifications. d)-f) Zr mappings of the fracture surfaces of porcelain-veneered Y-TZP for different surface modifications. Si concentrations in the cohesive failure area and outside the area are clearly different. 
a) Surface modified area

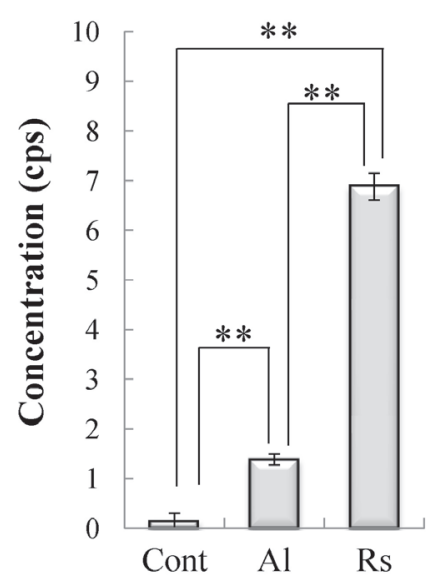

b) Failure area

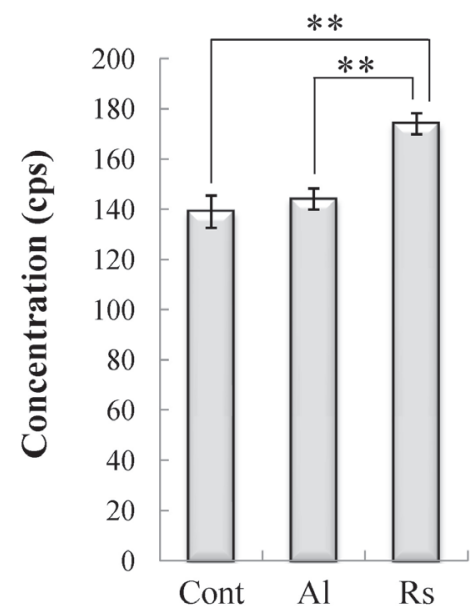

Fig. 6 a) Distribution and standard deviation of Si concentration on Y-TZP surfaces for each surface modification. b) Distribution of Si concentration over the fracture surfaces. Statistically significant differences within the groups are marked. $* *:(p<0.01)$.

surfaces. The silica-coated area found indicates that $\mathrm{Si}$ particles remain after surface modification. Furthermore, $\mathrm{Zr}$ particles were clearly found on all surface modified areas, as seen in Fig. 4-b). Thus, the silicate layer formed by silica coating is very thin. Figure 5 -a) and d) show $\mathrm{Si}$ and $\mathrm{Zr}$ mappings of the fracture surfaces of the control, Fig. 5-b) and e) show Si and Zr mappings of the fracture surfaces of the alumina-sandblasted specimen, and Fig. 5-c) and f) show $\mathrm{Si}$ and $\mathrm{Zr}$ mappings of the fracture surfaces of the silica-coated specimen after the three-point bending test. Figure 6-a) shows the amount of $\mathrm{Si}$ deposited on each surface-modified specimen. For the $\mathrm{Rs}$ sample, the mean $\mathrm{Si}$ concentration was $6.88 \pm 0.27$ cps, which was significantly higher than the Al sample (1.38 $\pm 0.11 \mathrm{cps})$, which was in turn significantly higher than and the control $(0.14 \pm 0.17 \mathrm{cps})(p<0.01)$.

Figure 6-b) shows the distribution of Si concentration on the fracture surface of each surface-modified sample. The Si concentration for the Rs sample was $174 \pm 4.18$ cps, which was significantly higher than the Al sample

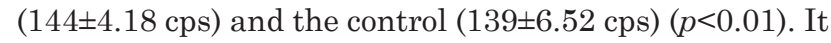
was evident that Si derived from the veneering porcelain remained in the failure area, as the Si concentration on the fracture surfaces was clearly higher than on the surface-modified area, thereby indicating adherence of remaining Si particles to the Y-TZP surface, even after the latter was subjected to the three-point bending test for bond strength measurements.

\section{DISCUSSION}

The Y-TZP surface was inspected via EPMA to determine if it was really effectively covered by silica-coating ${ }^{33,34)}$. The silica concentration of the silica-coated area was significantly higher than other areas based on the mean value of the $\mathrm{Si}$ concentration (Fig. 6-a). The Si concentration increased in only the silica-coated area in a Si mapping image (Fig. 4-a). Therefore, it is inferred that the silicate layer was formed on the Y-TZP surface by the silica-coating method. Previously, Kern et al. ${ }^{25,26)}$ indicated that the silica-coating method is capable of forming a thin silicate layer on dental ceramics, including a zirconia surface. In addition, the Si concentration of a fractured surface (Fig. 5) increased in comparison with the value obtained before a layer of porcelain was applied (Fig. 4-a). In contrast, the $\mathrm{Zr}$ concentration of the fractured surface (Fig. 5) was decreased in comparison with the value obtained before a layer of porcelain was applied (Fig. 4-b). The increase in the Si concentration of fractured Y-TZP surfaces after the three-point bending test was not due to the silicate layer formed by silicacoating. Rather, the Si of the veneering porcelain which remained on the Y-TZP surfaces that was detected was inferred to be so strongly bonded that it prevented detection of $\mathrm{Zr}$ in the cohesive failure area. Therefore, as has been shown previously ${ }^{35)}$, it is concluded that the interface of the Y-TZP and the veneering porcelain is bonded strongly, and it is thought that fracture occurs in the inside of the veneering porcelain. Similarly, Fischer et $a l .{ }^{13)}$ indicated that the bond strength of the interface was higher than the cohesive strength of the ceramic, and it was concluded that the veneering ceramic was the weakest link. To realize the benefit of the high strength of the zirconia framework, the strength of veneering ceramics must be improved.

Mechanical or chemical surface treatments promote an increase in the porosity and roughness of dental ceramics, improving wettability ${ }^{36,37)}$. Rougher surfaces have wider contact areas available for bonding, and also provide for an increased surface free energy in comparison to flatter or smoother surfaces ${ }^{34,35)}$. Thus, the surface roughness value and surface free energy of Y-TZP 
samples were inspected in samples with varying surface modifications. As a result of EPMA (Fig. 4), it is inferred that a silica layer was formed on the Y-TZP surface by silica-coating to Y-TZP. As shown in Fig.2, Table 3, the surface free energy of all surface-modified groups was significantly higher than the control group $(p<0.01)$. In particular, silica-coating (Rs group) was higher than any other groups $(p<0.01)$. And it is inferred that the wettability increased by the Y-TZP surface which a silica layer was formed becomes hydrophilic. On the other hand, Table 4 shows that the silica-coated Rs group had lower surface roughness values ( $\mathrm{Ra}$ and $\mathrm{Rz}$ ) than the alumina-sandblasted (Al) or silica-coated (Rp) groups. Therefore, the silica-coating $(\mathrm{Rs})$ did not merely roughen the Y-TZP mechanically, it also increased the wettability of the Y-TZP. Furthermore, veneering porcelain became easy to match with the Y-TZP surface due to improved wettability, when porcelain was layered and annealed on the Y-TZP surface.

One manufacturer (Vita Zahnfabrik, Bad Säckingen, Germany) recommends heat treatment of the zirconia framework after surface modifications in order to reverse any phase transformations. This has been performed by others ${ }^{23)}$, reversing the monoclinic to the tetragonal phase transformation in order to retrieve the coefficient of thermal expansion of the tetragonal zirconia and release tensile stresses after sandblasting or grinding, thereby obtaining better bond strength. In the present study, the XRD patterns (Fig. 1) show that the phase transformation from tetragonal to monoclinic zirconia of the Y-TZP surface was caused by mechanical surface modification. But, Table 2 shows that there was little monoclinic zirconia after surface modification. In comparison to another study ${ }^{24)}$ that employed the same test design to investigate the volume of monoclinic zirconia (4.5 vol\% after alumina sandblasting and 10.2 vol\% after silica coating), the amount obtained in the present investigation (Table 2) was less. In addition, the volume of monoclinic zirconia found here decreased after heat treatment following surface modification. It is believed that the volume of monoclinic zirconia depends greatly on the surface modification conditions, because particle size, blast pressure and blast time are different in each study.

Surface modifications were examined for their influence on flexural strength and bond strength in porcelain-veneered Y-TZP following ISO 9693, the international standard on metal-ceramic dental restorative systems. From the graph showing the bond strength between the Y-TZP and the veneering porcelain (Fig. 3-a, Table 5), it is seen that all of the surfacemodified groups and the control group show a bond strength of more than $25 \mathrm{MPa}$, the prescribed minimum of ISO $9693^{27,28)}$. On the other hand, in case of aluminasandblasted, the bond strength of $\mathrm{Al}$ was not significantly different to Al.h and control. Furthermore, in case of silica-coated, there was not significantly different between $\mathrm{Rs}$ and Rs.h, Rp and Rp.h. Therefore it is inferred that there is not effect of the heat treatment. However, only the $30 \mu \mathrm{m}$ silica-coated group (Rs, Rs.h) was significantly higher in bond strength than the control group, though this is not due to heat treatment, as mentioned above because no significant difference in bond strength following heat treatment was observed. Thus, it is inferred that there is an effect of $30 \mu \mathrm{m}$ silicacoated without heat treatment. Furthermore the high bond strength obtained here is presumably due to the surface modification conditions $(10 \mathrm{~s}, 0.4 \mathrm{MPa})$, which did not cause an increase the amount of monoclinic zirconia, which results in reduced bond strength between Y-TZP and veneered porcelains.

The manufacturer recommends heat treatment of the zirconia framework in order to enhance bond strength and flexural strength after sandblasting or grinding. However, the present study finds that the flexural strength of Y-TZP does not vary significantly for any surface modification. Therefore, the heat treatment recommendation may not be necessary in present study.

Thus, it is concluded that surface modification effects depend on particle size and blast pressure. Furthermore, heat treatment after surface modification may not be necessary, because no significant changes in the bond strength or flexural strength were observed. In addition, it was found that the silica-coating $(30 \mu \mathrm{m})$ method of surface modification moderately roughened the Y-TZP surface, improving the surface wettability while maintaining the strength of the Y-TZP, thereby making the Y-TZP surface easy to match with veneering porcelain and enhancing the bond strength. Therefore, the $30 \mu \mathrm{m}$ silica-coating method of surface modification is recommended for the pre-treatment of a veneered porcelain Y-TZP surface.

\section{REFERENCES}

1) Pittayachawan P, McDonald A, Petrie A, Knowles JC. The biaxial flexural strength and fatigue property of Lava Y-TZP dental ceramic. Dent Mater 2007; 23: 1018-1029.

2) Christel P, Meunier A, Heller M, Torre JP, Peille CN. Mechanical properties and short-term in-vivo evaluation of yttrium-oxide-partially-stabilized zirconia. J Biomed Mater Res 1989; 23: 45-61.

3) Guess PC, Kulis A, Witkowski S, Wolkewitz M, Zhang Y, Strub JR. Shear bond strengths between different zirconia cores and veneering ceramics and their susceptibility to thermocycling. Dent Mater 2008; 24: 1556-1567.

4) Tinschert J, Zwez D, Marx R, Anusavice KJ. Structural reliability of alumina-, feldspar-, leucite-, mica- and zirconiabased ceramics. J Dent 2000; 28: 529-535.

5) Karakoca S, Yilmaz H. Influence of surface treatments on surface roughness, phase transformation, and biaxial flexural strength of Y-TZP ceramics. J Biomed Mater Res B Appl Biomater 2009; 91: 930-937.

6) Kosmac T, Oblak C, Jevnikar P, Funduk N, Marion L. The effect of surface grinding and sandblasting on flexural strength and reliability of Y-TZP zirconia ceramic. Dent Mater 1999; 15: 426-433.

7) Chevalier J. What future for zirconia as a biomaterial? Biomaterials 2006; 27: 535-543.

8) Denry IL, Holloway JA. Microstructural and crystallographic surface changes after grinding zirconia-based dental ceramics. J Biomed Mater Res B Appl Biomater 2006; 76 : 440-448.

9) Deville S, Chevalier J, Gremillard L. Influence of surface 
finish and residual stresses on the ageing sensitivity of biomedical grade zirconia. Biomaterials 2006; 27: 2186-2192.

10) Luthardt RG, Holzhuter M, Sandkuhl O, Herold V, Schnapp JD, Kuhlisch E, Walter M. Reliability and properties of ground Y-TZP-zirconia ceramics. J Dent Res 2002; 81: 487-491.

11) Oblak C, Jevnikar P, Kosmac T, Funduk N, Marion L. Fracture resistance and reliability of new zirconia posts. J Prosthet Dent 2004; 91: 342-348.

12) Kosmac T, Oblak C, Marion L. The effects of dental grinding and sandblasting on ageing and fatigue behavior of dental zirconia (Y-TZP) ceramics. J Eur Ceram Soc 2007; 28: 1085-1090.

13) Fischer J, Grohmann P, Stawarczyk B. Effect of zirconia surface treatments on the shear strength of zirconia/ veneering ceramic composites. Dent Mater J 2008; 27: 448-454.

14) Kosmac T, Oblak C, Jevnikar P, Funduk N, Marion L. Strength and reliability of surface treated Y-TZP dental ceramics. J Biomed Mater Res 2000; 53: 304-313.

15) Evans AG. Perspective on the development of high-toughness ceramics. J Am Ceram Soc 1990; 73: 187-206.

16) Guazzato M, Albakry M, Quach L, Swain MV. Influence of grinding, sandblasting, polishing and heat treatment on the flexural strength of a glass-infiltrated alumina-reinforced dental ceramic. Biomaterials 2004; 25: 2153-2160.

17) Swain MV. Grinding-induced tempering of ceramics containing metastable tetragonal zirconia. J Mater Sci 1980; 15: $1577-1579$.

18) Aboushelib MN, de Jager N, Kleverlaan CJ, Feilzer AJ. Microtensile bond strength of different components of core veneered all-ceramic restorations. Dent Mater 2005; 21: 984-991.

19) Reed JS, Lejus AM. Effect of grinding and polishing on near-surface phase transformations in zirconia. Mat Res Bull 1977; 12: 949-954.

20) Zhang Y, Lawn BR, Rekow ED, Thompson VP. Effect of sandblasting on the long-term performance of dental ceramics. J Biomed Mater Res B Appl Biomater 2004; 71: 381-386.

21) Fischer J, Stawarczyk B. Compatibility of machined Ce-TZP/ $\mathrm{Al}_{2} \mathrm{O}_{3}$ nanocomposite and a veneering ceramic. Dent Mater 2007; 23: 1500-1505.

22) Zhang Y, Lawn BR, Malament KA, Van Thompson P, Rekow ED. Damage accumulation and fatigue life of particle-abraded ceramics. Int J Prosthodont 2006; 19: 442-448.

23) Vita Z. Veneering material VitaVM9. Working instructions.
Vita Zahnfabrik, Bad Säckingen, 2007.

24) Sato H, Yamada K, Pezzotti G, Nawa M, Ban S. Mechanical properties of dental zirconia ceramics changed with sandblasting and heat treatment. Dent Mater J 2008; 27: 408-414.

25) Kern M, Thompson VP. Sandblasting and silica coating of a glass-infiltrated alumina ceramic: volume loss, morphology, and changes in the surface composition. J Prosthet Dent 1994; 71: 453-461.

26) Kern M, Wegner SM. Bonding to zirconia ceramic: adhesion methods and their durability. Dent Mater 1998; 14: 64-71.

27) International Organization Standardization. Metal-ceramic dental restorative systems: ISO 9693. ISO, 1999.

28) Kuriyama S, Terui Y, Higuchi D, Goto D, Hotta Y, Manabe A, Miyazaki T. Novel fabrication method for zirconia restorations: Bonding strength of machinable ceramic to zirconia with resin cements. Dent Mater J 2011; 30: 419-424.

29) Ban S. Reliability and properties of core materials for all-ceramic dental restorations. Jpn Dent Sci Rev 2008; 44: 3-21.

30) Garvie RC, Nicholson PS. Phase analysis in zirconia systems. J Am Ceram Soc 1972; 55: 303-305.

31) Toraya H, Yoshimura M, Somiya S. Calibration curve for quantitative analysis of the monoclinic-tetragonal $\mathrm{ZrO}_{2}$ System by X-ray diffraction. J Am Ceram Soc 1984; 67: C119-C121.

32) Owens DK, Wendt RC. Estimation of the surface free energy of polymers. J Appl Polym Sci 1969; 13: 1741-1747.

33) Katsumata Y, Hojo S, Hamano N, Watanabe T, Yamaguchi H, Okada S, Teranaka T, Ino S. Bonding strength of autopolymerizing resin to nylon denture base polymer. Dent Mater J 2009; 28: 409-418.

34) Watanabe T, Ino S, Okada S, Katsumata Y, Hamano N, Hojo $\mathrm{S}$, Teranaka T, Toyoda M. Influence of simplified silica coating method on the bonding strength of resin cement to dental alloy. Dent Mater J 2008; 27: 16-20.

35) Nakamura T, Wakabayashi K, Zaima C, Nishida H, Kinuta S, Yatani H. Tensile bond strength between tooth-colored porcelain and sandblasted zirconia framework. J Prosthodont Res 2009; 53: 116-119.

36) Eick JD, Johnson LN, Fromer JR, Good RJ, Neumann AW. Surface topography: its influence on wetting and adhesion in a dental adhesive system. J Dent Res 1972; 51: 780-788.

37) Pazinatto FB, Lopes FA, Marquezini Jr L, de Castro FLA, Atta MT. Effect of surface treatments on the spreading velocity simplified adhesive systems. J Appl Oral Sci 2006; 14: $393-398$ 